Research Article

\title{
Finite Element Analysis of RC Beams by the Discrete Model and CBIS Model Using LS-DYNA
}

\author{
Seung H. Yang, ${ }^{1}$ Kwang S. Woo, ${ }^{2}$ Jeong J. Kim, ${ }^{2}$ and Jae S. Ahn ${ }^{3}{ }^{3}$ \\ ${ }^{1}$ National Disaster Management Research Institute, 365 Jongga-Ro, Jung-gu, Ulsan 44538, Republic of Korea \\ ${ }^{2}$ Department of Civil Engineering, Yeungnam University, 280 Daehak-Ro, Gyeongsan, Gyeonbuk 38541, Republic of Korea \\ ${ }^{3}$ School of General Education, Yeungnam University, 280 Daehak-Ro, Gyeongsan, Gyeonbuk 38541, Republic of Korea
}

Correspondence should be addressed to Jae S. Ahn; jsahn@ynu.ac.kr

Received 2 September 2020; Revised 18 January 2021; Accepted 10 February 2021; Published 24 February 2021

Academic Editor: Francesco Colangelo

Copyright (c) 2021 Seung H. Yang et al. This is an open access article distributed under the Creative Commons Attribution License, which permits unrestricted use, distribution, and reproduction in any medium, provided the original work is properly cited.

\begin{abstract}
There are several techniques to simulate rebar reinforced concrete, such as smeared model, discrete model, embedded model, CLIS (constrained Lagrange in solid) model, and CBIS (constrained beam in solid) model. In this study, however, the interaction between the concrete elements and the reinforcement beam elements is only simulated by the discrete model and CBIS (constrained beam in solid) model. The efficiency and accuracy comparisons are investigated with reference to the analysis results by both models provided by LS-DYNA explicit finite element software. The geometric models are created using LS-PrePost, general purpose preprocessing software for meshing. The meshed models are imported to LS-DYNA where the input files are then analyzed. Winfrith and CSCM concrete material options are employed to describe the concrete damage behavior. The reinforcement material model is capable of isotropic and kinematic hardening plasticity. The load versus midspan deflection curves of the finite element models correlate with those of the experiment. Under the conditions of the same level of accuracy, the CBIS model is evaluated to have the following advantages over the discrete model. First, it has the advantage of reducing the time required for FE modeling; second, saving computer CPU time due to a reduction in total number of nodes; and third, securing a good aspect ratio of concrete elements.
\end{abstract}

\section{Introduction}

Finite element method is one of the most accurate and effective techniques for analyzing complicated structural engineering problems like reinforced concrete, which provides a convenient and adaptable tool for covering the problems associated with the analysis of the reinforced concrete. A number of numerical models have been proposed for the analysis of the reinforced concrete structures but none of them has managed to provide the desired combination, at an acceptable level, of accuracy, robustness, and computational efficiency in prediction the nonlinear inelastic behavior of different types of the reinforced concrete structures [1-3]. One-dimensional beam elements based on either concentrated plasticity models [4] or distributed plasticity [5] have difficulties in predicting the mechanical behavior of three-dimensional framed structures of the reinforced concrete due to their inability in capturing shear behavior and local phenomena that affect the global response of the structure. The use of two-dimensional plane stress finite elements $[6,7]$ can avoid some simplified assumption that are inherent in the one-dimensional beam elements like the influence of shear stresses but their inability of capturing the out of plane response made them inadequate for three-dimensional full-scale structural analysis. Three-dimensional analysis with solid finite elements based on triaxial stress-strain relationship and embedded rebars provides the highest quality of approximation, but it is hindered with high computational cost and in several cases lack of robustness $[8,9]$. The computational complexity of some models and the use of numerically unstable material models such as the smeared crack approach in concrete make their use impractical for full-scale analysis. These difficulties led a number of 
researchers to use various material models and different elements in order for the analysis of real-scale reinforced concrete structures to proceed with an acceptable accuracy and numerical robustness [9-11]. Currently, many researchers have used commercial codes such as ABAQUS, ANSYS, and LS-DYNA for modeling of real-scale reinforced concrete structures. Three softwares (ABAQUS, ANSYS, and LS-DYNA) are compared in a study by Cotsovos et al. [12]. The numerical study which uses eight-noded hexahedral isoparametric elements combined with two-noded rod elements for the reinforcement showed that very fine meshes (1-3 cm hexahedral edge size) were required, and thus the modeling was still impractical for real-scale reinforced structures. Meanwhile, in LS-DYNA, the most popular choice for modeling concrete in three dimensions is to use an eightnoded hexahedral element with a suitable integration scheme to control the zero energy modes or hourglassing. On the other hand, reinforcing steels in concrete are idealized using one-dimensional beam elements $[13,14]$. There are several ways to model a beam in which reinforcement is placed in concrete. The first approach is the distributed or smeared representation, in which the reinforcement is assumed to be distributed over the concrete element in the appropriate direction. This is a method of substituting a layer having an equivalent thickness as much as the number of reinforcing bars arranged. This method is the simplest method, but it has limitations in expressing local failure patterns such as cracks in the concrete area around the rebar. The second approach is a discrete model. In the discrete representation, the concrete elements and bar elements share common nodes shown in Figure 1. Full bond is generally assumed between concrete and steel. In some cases, linkage elements having a spring stiffness determined by a specific bond-slip relationship may also be defined. In the discrete model, the common nodes between the beam element for one-dimensional flexural and shear reinforcement and the solid element for three-dimensional concrete must be shared. As finite element discretization progresses, it takes a considerable amount of time for the mesh design to satisfy the node sharing. The third approach is an embedded element as shown in Figure 2. The reinforcing steel is considered as an axial member built into the isoparametric element such that its displacements are consistent with those of the concrete element. Such a model again implies a perfect bond between concrete and steel [15]. The fourth approach, adopted in this study, is a CBIS (constrained beam in solid) model by coupling of the reinforcement with the concrete solid elements using the keyword * Constrained_Beam_In_Solid [16] in LS-DYNA. It is to apply constrains between two sets of nodes. One is for beams and another for solids. This way, we avoid the meshing difficulties in the discrete model. The CBIS model as shown in Figure 3 is an enhanced algorithm compared with the CLIS (constrained Lagrange in solid) model that has been used to perform ALE fluid-structure interactions. As the beam mesh is too coarse to be directly coupled to the solid elements, a "slave beam" is constructed in between to couple both the "master beam" and the "master solid." Now, we have two couplings. The first is between the "slave beam" and the "master beam" and the second between the "slave beam" and

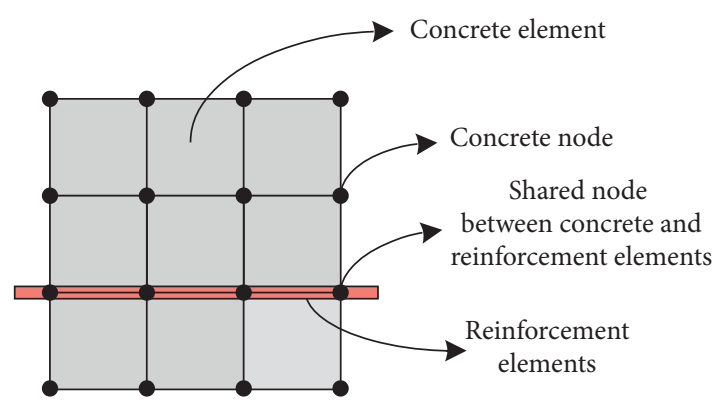

FIGURE 1: Shared common nodes between concrete solid element and reinforcement beam element (discrete model).

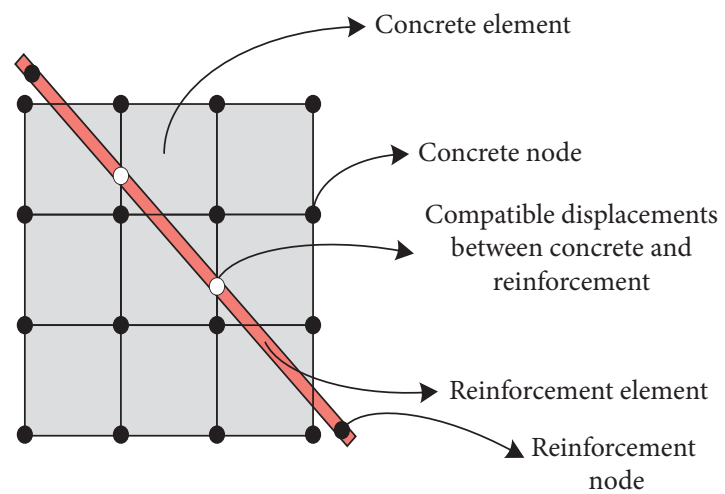

FIgURE 2: Reinforcement is placed embedded in concrete solid (embedded model).

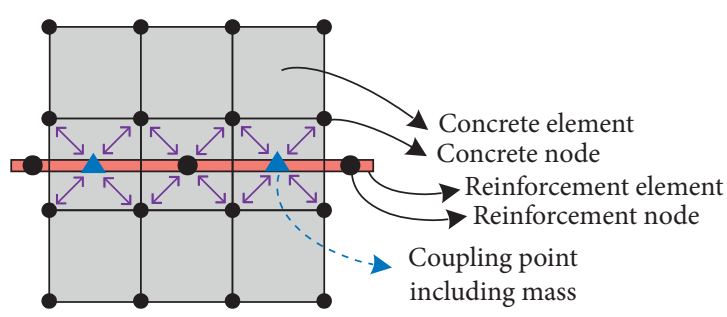

$\leftrightarrow \begin{aligned} \text { :Compatible displacements } \\ \text { between concrete and } \\ \text { reinforcement }\end{aligned}$

FIgURE 3: Concept of the CBIS model using coupling points including mass.

the solid mesh. Thus, "slave beam" serves as a "bridge" connecting the real beam and solid elements.

This study intends to evaluate the adequacy of the two models by applying the discrete model and CBIS model for the analysis of reinforced concrete beams under static load. To this end, Winfrith concrete material option (Material Model 84) and CSCM concrete material option (Material Model 159) are adopted among various material options that can consider concrete damage in LS-DYNA. In addition, Material Model 3 is used for the reinforcement of steel that can be capable of isotropic and kinematic hardening plasticity. It is a relatively simple bilinear model as compared with other material models for steel but is very cost effective in computational resources. The main objective of this study 
is to carry out a numerical analysis of reinforced concrete beams subjected to static loading. Comparison between the CBIS model and discrete model has been investigated from the viewpoint of convergence rate, accuracy, and modeling efficiency. Also, it is to investigate the use of the CBIS algorithm in modeling the interaction between concrete beam elements and reinforcement elements and to compare the finite element analysis based on the CBIS model with the numerical results by the discrete model, the results of the VecTor 4 program developed by the smeared model, and the experimental results conducted at the University of Toronto $[17,18]$.

\section{Description of RC Beam Experimental Tests}

The reinforced concrete beam was set up by Vecchio and Shim [17]. In this paper, the behavior of the beam is analyzed when the concentrated load is applied at the center of 12 types of simple beams classified according to the reinforcement arrangement and concrete beam size. The twelve simple beams are identical to the experimental specimens used by Bresler and Scordelis [19]. Considering that the rebar standards are different from those at the time, experiments have been carried out with new test RC beam specimens. Therefore, the word VS is added to the model name, which is derived from the author's name (Vecchio and Shim), to distinguish it from the test subjects of Bresler and Scordelis [19]. The twelve different models were classified according to the concrete compressive strength, span length, section width, and reinforcement type. However, the failure behavior, which is the result of the test, is classified into three groups according to the span length and stirrup reinforcement. First, the group of beams without shear reinforcement is failed by diagonal shear cracks. Second, the failure of the short span beam $(3660 \mathrm{~mm})$ or medium length span beam $(4570 \mathrm{~mm})$ reinforced with stirrups is caused by shear compression stress. Third, the failure of the long span $(6400 \mathrm{~mm})$ beam reinforced with stirrups is caused by bending compression stress. In this study, the A3 model with the largest cross-sectional width among the third group in which bending compressive stress predominates has been adopted as an example of finite element analysis. The reinforced concrete beams were set up by Vecchio and Shim [17]. In the beam test, reinforced concrete beams are subjected to a static loading. A specimen is simply supported on both ends by two short steel columns at $6400 \mathrm{~mm}$ span. A specimen has a self-weight of $23 \mathrm{kN} / \mathrm{m}^{3}$. The beam has a concrete cover of $61 \mathrm{~mm}$. The details of VS-A3 beam are shown in Figure 4. The loading is applied to the beams and increased monotonically in small increments to failure.

\section{Finite Element Modeling of the Reinforced Concrete Beam}

The implicit method is suitable for static analysis, but due to its noncapability to handle nonlinearities, explicit analysis has been employed to perform the analysis. The geometry of concrete beam, loading plate, and reinforcement is first developed using LS-PrePost software. The material models are defined by LS-PrePost software program. The mesh design is shown in Figure 5. The concrete solid parts and rigid load plate are modeled in LS-DYNA using cubic eightnode hexahedron elements. Both the solid and rigid elements have employed one-point Gauss integration designated as "ELFORM 1" which is an under integrated element formulation. To avoid spurious modes in the solid element, hourglass control (stiffness-based) formulation is also used. Reinforcement bars are modeled with one-dimensional beam element, which provides bending stiffness, and the two-node Hughes-Liu beam element formulation with $2 \times 2$ Gauss integration has been employed in the modeling.

3.1. Material Models. Material models, Mat 159 model (CSCM_concrete card) and Mat 84 model (Winfrith_concrete card) are used to characterize the concrete damage behavior. The main feature of the Mat 159 model is that the shear failure and compaction surface are "mixed" together to form a smooth or continuous surface [20]. The material rate effects are modeled with viscoplasticity. An element loses its strength and stiffness once the damage accumulation would be equal to unity [21]. The model is mesh insensitive and maintains constant fracture energy regardless of the element size [21]. The Mat 84 model in LS-DYNA is a basic plasticity model with a Mohr-Coulomb behavior with a third stress invariant to treat the triaxial extension in both tension and compression, and the damage in tension has a strain behavior to make the material more regular via crack width, fracture energy, and aggregate size [22]. In LS-DYNA, there are two versions of Winfrith concrete material option. The first is where the concrete can be modeled with smeared fixed crack, and the second is where the reinforcement can be modeled explicitly into the concrete, and strain rate effect can be included or excluded in this option. A rigid material model, Mat 020-Rigid is used to model a loading plate. To capture interaction between concrete solid element and support/rigid load plate element, contact surface was defined using the algorithm Contact Automatic_Surfacs_To_Surface. This contact uses the penalty method and allows for compression loads to be transferred between the slave nodes and the master segments.

The material model, Mat 003-Plastic_Kinematic has been employed to model the reinforcement bars. It has the options to integrate rate effects and kinematic or isotropic hardening rules [21]. The interaction between the concrete solid elements and reinforcement beam elements is achieved by use of constrained beam in solid (CBIS) option card in LS-DYNA. It functions by coupling the beam elements to the solids and making motions of both uniform [22]. Tables 1 and 2 show the material properties of the concrete and reinforcement of the VS-A3 RC beam adopted in this study.

3.2. Boundary Condition and Load Application. The concrete beams are simply supported at $6400 \mathrm{~mm}$ span. The loads are placed at a distance of $3200 \mathrm{~mm}$ from the support position in Figure 4. The numerical simulations are based on the displacement control. Once concentrated loads are placed on the rigid loading plates located on top of the concrete solid beam, a displacement is prescribed to them linearly. In order 


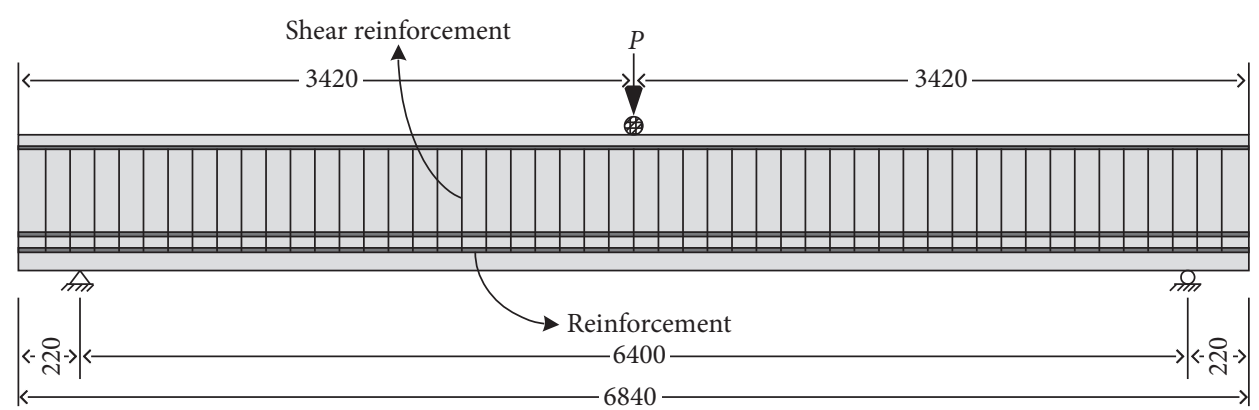

(a)

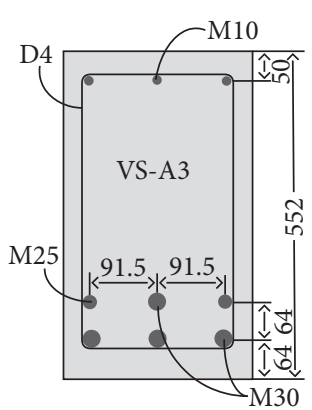

(b)

FIgURE 4: The geometry and reinforcement details of VS-A3 beam [17].

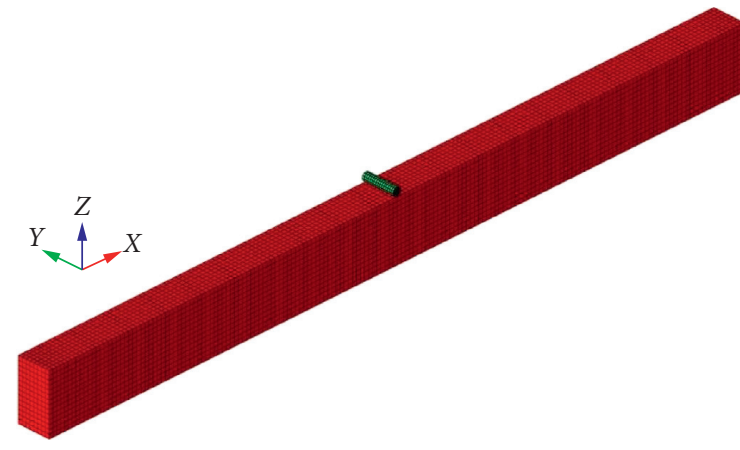

(a)

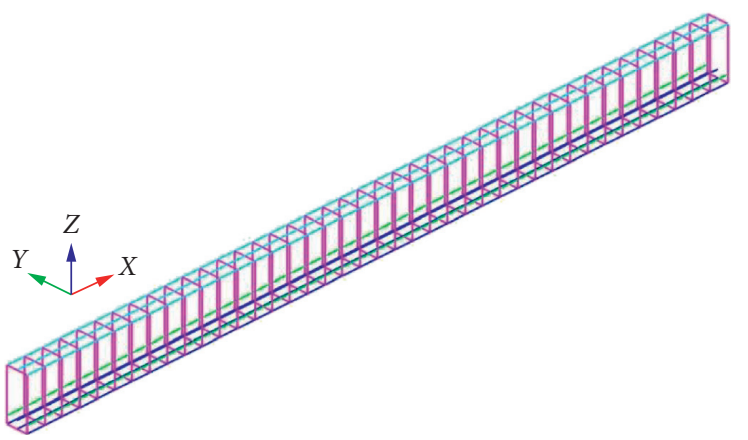

(b)

FIGURE 5: Mesh design for concrete solids and reinforcement bars.

Table 1: Concrete material properties.

\begin{tabular}{|c|c|c|c|c|c|c|}
\hline Beam & Age (days) & Uniaxial compressive stress $(\mathrm{MPa})$ & Elastic modulus (MPa) & $\begin{array}{c}\text { Fracture energy, } G_{\mathrm{F}} \\
(\mathrm{N} / \mathrm{mm})\end{array}$ & Density $\left(\mathrm{t} / \mathrm{mm}^{3}\right)$ & Poisson's ratio \\
\hline $\begin{array}{l}\text { VS- } \\
\text { A3 }\end{array}$ & 127 & 43.5 & 34300 & 0.115 & $2.3 \times 10^{-9}$ & 0.3 \\
\hline
\end{tabular}

TABLE 2: Reinforcement material properties.

\begin{tabular}{lcccc}
\hline Beams & Density $\left(\mathrm{t} / \mathrm{mm}^{3}\right)$ & Elastic modulus $(\mathrm{MPa})$ & Steel strength, $(\mathrm{MPa})$ & Poisson's ratio \\
\hline M30 & $7.8 \times 10^{-9}$ & 200000 & 436 & 0.3 \\
M25 & $7.8 \times 10^{-9}$ & 220000 & 445 & 0.3 \\
M10 & $7.8 \times 10^{-9}$ & 200000 & 315 & 0.3 \\
D4 & $7.8 \times 10^{-9}$ & 200000 & 600 & 0.3 \\
\hline
\end{tabular}

to avoid effects of inertial, the loading time has been chosen as $1.0 \mathrm{sec}$. It is noted that a load application time of $1.0 \mathrm{sec}$ seems to be sufficiently long so that inertial effects are negligible and the analysis can be used to represent a quasistatic experiment [23]. The displacement is prescribed from 0 at $t=0.0 \mathrm{sec}$ to $80 \mathrm{~mm}$ at $t=1.0 \mathrm{sec}$. The corresponding loads are recorded in the simulation using DATABASE and ASCII output keywords.

3.3. Mesh Sensitivity Study. The preprocessor of HYPERMESH program has been used to create nonuniform mesh sizes ranging from 16.7 to $80 \mathrm{~mm}$ to investigate mesh discretization sensitivity. Series of analysis are carried out using the four different mesh patterns, and the concrete solid beam and reinforcement beam with the finer mesh prove to be sensitive. In the discrete model, the common nodes of reinforcement and concrete are shared. In order to share the common nodes, the concrete and the reinforcing bars have to be divided into elements considering the node positions of each other. Then, the size of the elements of reinforcing bars and concrete will not be uniform, as shown in Table 3. As a result, there is a high probability of deteriorating the aspect ratio of elements, so a large number of fine elements must be used. On the other hand, the uniform mesh refinement is possible since the CBIS model does not need to share the 
TABle 3: Mesh data for the discrete model.

\begin{tabular}{lcccc}
\hline Discrete model & Very fine mesh & Fine mesh & Normal mesh & Coarse mesh \\
\hline Total nodes & 149205 & 23355 & 9030 & 3915 \\
Solid elements & 134064 & 19264 & 6912 & 1982 \\
Beam elements & 5340 & 2670 & $60 \times 53 \times 50$ & 1376 \\
& $20 \times 20 \times 16.7$ & $40 \times 45 \times 50$ & $62 \times 53 \times 45$ & $92 \times 80 \times 75$ \\
Solid element size $(\mathrm{mm})$ & $20 \times 20 \times 20$ & $40 \times 45 \times 42$ & $53 \times 50 \times 45$ & $82 \times 80 \times 50$ \\
& 20 & $30 \times 40 \times 50$ & $62 / 53 / 45$ & $92 / 80 / 75$ \\
\hline
\end{tabular}

position of nodes as shown in Table 4. Thus, it is possible to maintain a good aspect ratio of solid elements. The mesh designs for the discrete model and CBIS model are presented in Figures 6 and 7 that consist of coarse, normal, fine, and very fine mesh types.

In the coarse mesh, both the discrete model and the CBIS model show an unstable shape due to severe oscillation of the load-midspan displacement $(P-\delta)$ curve. On the other hand, both models by using normal mesh seem to converge well as shown in Figures 8 and 9, but they also show somewhat oscillation for the CBIS model. In the case of the CBIS model, the $P$ - $\delta$ curve of the fine mesh and the very fine mesh is almost identical as shown in Figure 9, whereas in the discrete model, a slight gap is detected between the loaddisplacement curves according to two different meshes as shown in Figure 8. Assuming that the finite element analysis by a very fine mesh is an exact solution, it cannot be judged that the fine mesh has yet converged.

To clarify this, a convergence test has been conducted on the maximum displacement of the beam center as the degree of freedom is increased. At this time, the ultimate load is applied. The CBIS model is converged on the fine mesh, but the discrete model did not converge, and additional analysis has been carried out between the fine mesh and the very fine mesh to confirm convergence. The discrete model converged at a $\log (\mathrm{NDF})$ value of 5.164, that is, $\mathrm{NDF}=145918$, and the CBIS model converged at a $\log (\mathrm{NDF})$ value of 4.845 , that is, $\mathrm{NDF}=70036$ as shown in Figure 10. As a result, it is confirmed that the CBIS model is converged at almost half the net degree of freedom (NDF) as compared with the discrete model.

\subsection{Finite Element Results and Comparisons with Test.} Figures 11-13 compare the numerical simulation results using Winfrith and CSCM with the test. The load versus midspan displacement curves of the finite element models correlate well with the experimental test. At displacement value of $77 \mathrm{~mm}$, the experimental curve drops down rapidly, which indicates failure of the longitudinal reinforcement. However, the Winfrith model and CSCM model continue to show ductility. In the linear elastic stage, the stiffness of the load-displacement curve by VecTor4 is also similar to the experimental result as well as the analysis results obtained by the CBIS model using not only the CSCM model but also the Winfrith concrete model. After yielding, the VecTor4 result is rapidly failed and it is difficult to confirm the behavior in the nonlinear stage. VecTor4 is a nonlinear finite element analysis program for reinforced concrete shell and slab structures. The most notable feature of program VecTor4 is the use of a layered thick-shell element formulation.

In the case of CSCM concrete material option, the numerical analysis results by the discrete model and the CBIS model show similar curve shape as well as stiffness in the linear region as shown in Figure 12. This result is valid even when using the Winfrith concrete option in Figure 13. It is observed that the discrete model using Winfrith concrete option shows a sudden drop phenomenon when the maximum displacement of the beam center reaches $74 \mathrm{~mm}$ in Figure 13. On the other hand, the CBIS model continues to show ductility. All finite element models are based on the very fine mesh design with the largest number of elements. As shown in the numerical analysis results, the discrete model and the CBIS model show similar levels of accuracy, so in the future example analysis, we will show the analysis results using only the CBIS model, which can significantly reduce the analysis time and is recommended in this study.

Also, cracking and ultimate loads of the finite element model are shown in Table 5. The ultimate load is calculated on the basis of the experiment value of $420 \mathrm{kN}$, VecTor4 is $406 \mathrm{kN}$, CBIS finite element model is $439 \mathrm{kN}$ when using CSCM concrete option, and $424 \mathrm{kN}$ when Winfrith concrete option is adopted. The Winfrith concrete model can predict the initiation of concrete cracks, and at the same time, the cracking load is calculated by $189 \mathrm{kN}$. As a result, the Winfrith material model has the advantage of being able to identify concrete cracks. Since the CBIS model is recommended in this study, the discrete model results are not calculated in Table 5.

The distribution of effective plastic strains and crack patterns obtained by the CBIS finite element model is shown in Figures 14 and 15. The effective plastic strain on the CSCM concrete model indicates the strain localization where failure propagates with $P=439 \mathrm{kN}$. In the model using the CSCM option, plastic deformation first occurs when the load is $73.8 \mathrm{kN}$, and then plastic deformation increases as the load is increased. At the stage of ultimate load $(P=439 \mathrm{kN})$, the plastic strain is increased to a certain extent without increasing the load. On the other hand, the Winfrith concrete model predicted flexural cracks at the center of RC beam when $P=424 \mathrm{kN}$ is applied. The crack is developed to some extent beyond $P=424 \mathrm{kN}$, and the shape of the crack did not increase any more. In addition, a crack with a depth of $395 \mathrm{~mm}$ in the height direction occurs in a concrete section whose lengthwise width is about $407 \mathrm{~mm}$ at the middle of the span. The penetration depth of $395 \mathrm{~mm}$ is 
Table 4: Mesh data for the CBIS model.

\begin{tabular}{lcccc}
\hline CBIS model & Very fine mesh & Fine mesh & Normal mesh & Coarse mesh \\
\hline Total nodes & 169099 & 23355 & 5750 & 4104 \\
Solid elements & 153216 & 19264 & 1783 & 2408 \\
Beam elements & 5422 & 2752 & $60 \times 60 \times 76$ & 1294 \\
Solid element size $(\mathrm{mm})$ & $20 \times 20 \times 20$ & $40 \times 40 \times 40$ & 40 & $60 \times 80 \times 76$ \\
Beam element size $(\mathrm{mm})$ & 20 & 40 & 80 \\
\hline
\end{tabular}

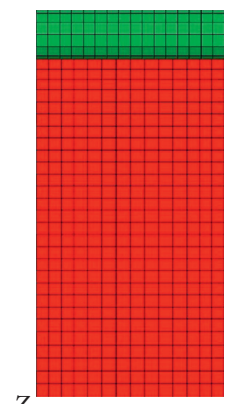

$\prod_{X}^{Z} \underset{Y}{ } \quad$ Very fine

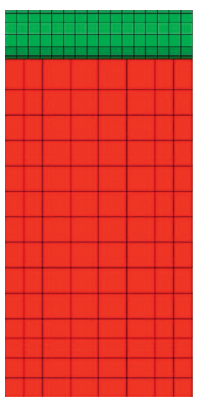

Fine

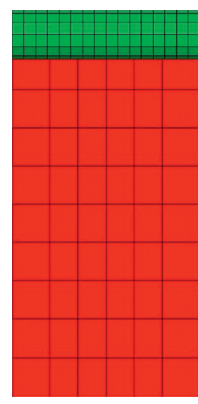

Normal

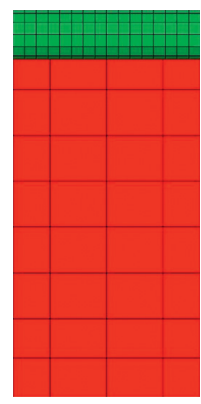

Coarse
Figure 6: Mesh design for the discrete model.

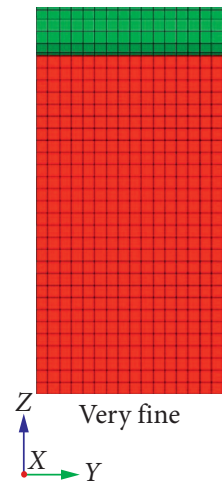

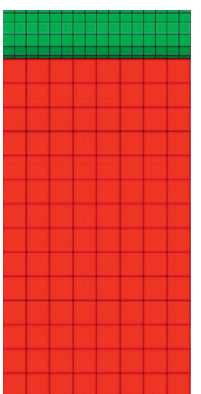

Fine

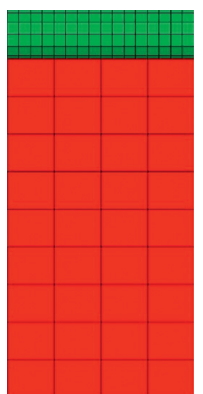

Normal

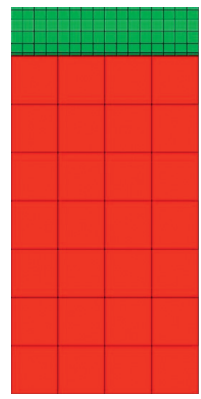

Coarse
Figure 7: Mesh design for the CBIS model.

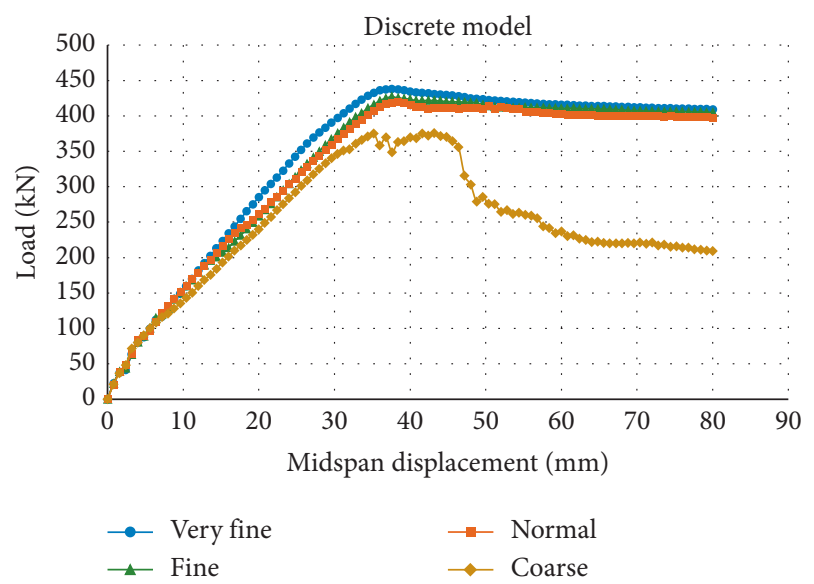

FIGURE 8: Mesh sensitivity results for the discrete model.

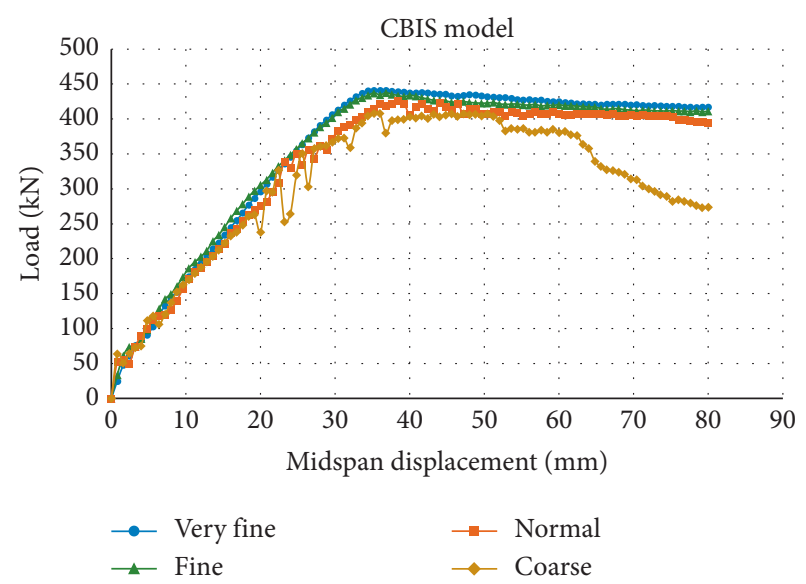

FIgURE 9: Mesh sensitivity results for the CBIS model.

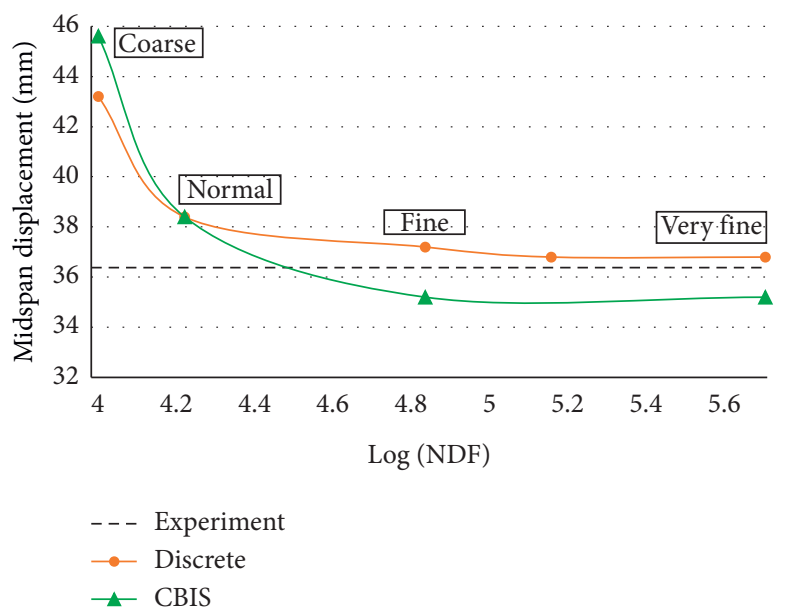

FIGURE 10: Convergence characteristics of midspan displacement with respect to the increase in NDF.

more than half of the height of the cross section of $552 \mathrm{~mm}$, and it is seen as a crack that plays a critical role in the collapse of RC beam.

The plastic deformation on the CSCM concrete model indicates the strain localization according to different loading stages where failure propagates as shown in Figure 16. Also, the cracks are initiated and progressed until the ultimate load level is reached in Figure 17. Crack patterns are obtained by use of Winfrith concrete material option. The numerical analysis indicates crack growth initiating from the midspan at the bottom of the reinforced concrete beams and 


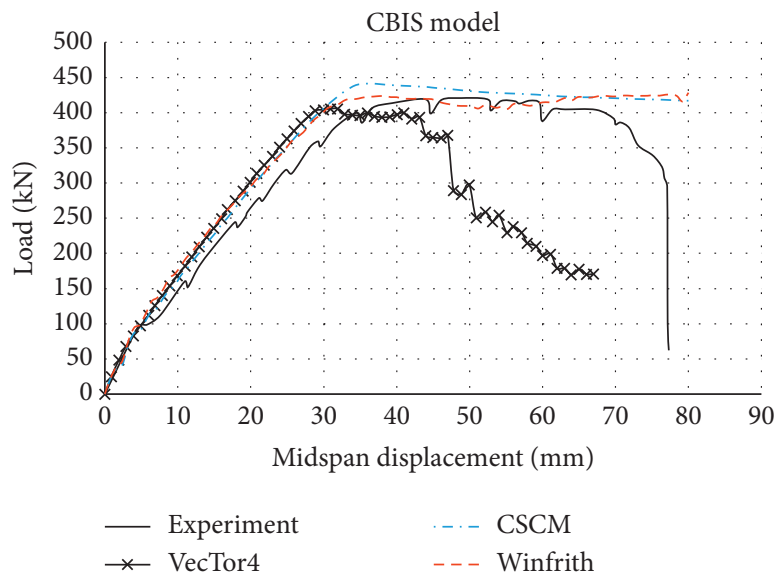

FIGURE 11: Numerical results by the CBIS model compared with the experimental test.

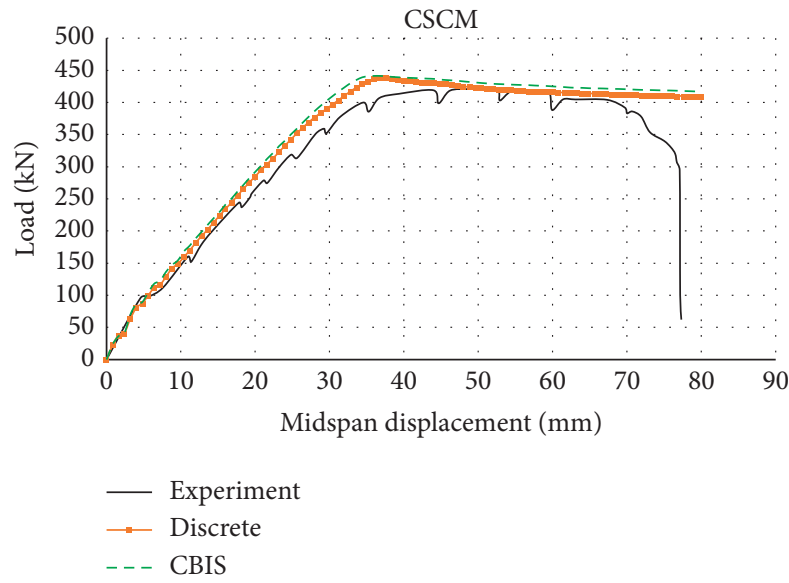

FIgURE 12: Comparison of the discrete model and CBIS model when CSCM concrete material option is used.
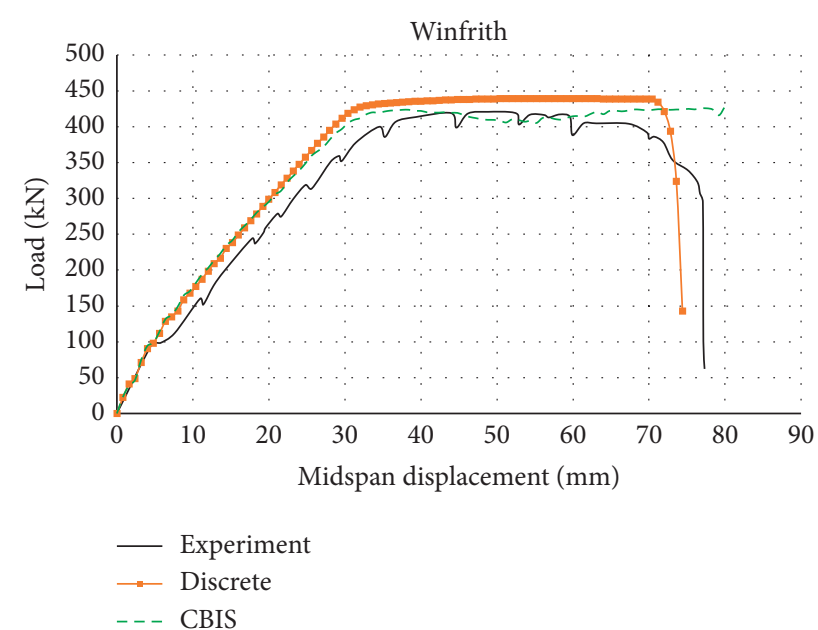

FIGURE 13: Comparison of the discrete model and CBIS model when Winfrith concrete material option is used. 
TABLE 5: Cracking and ultimate load.

\begin{tabular}{lcccc}
\hline Experiment & VecTor4 & & CBIS FE model \\
Ultimate load & Ultimate load & CSCM & Winfrith \\
\hline $420 \mathrm{kN}$ & $406 \mathrm{kN}$ & Ultimate load & Cracking load (kN) & Ultimate load \\
\hline
\end{tabular}

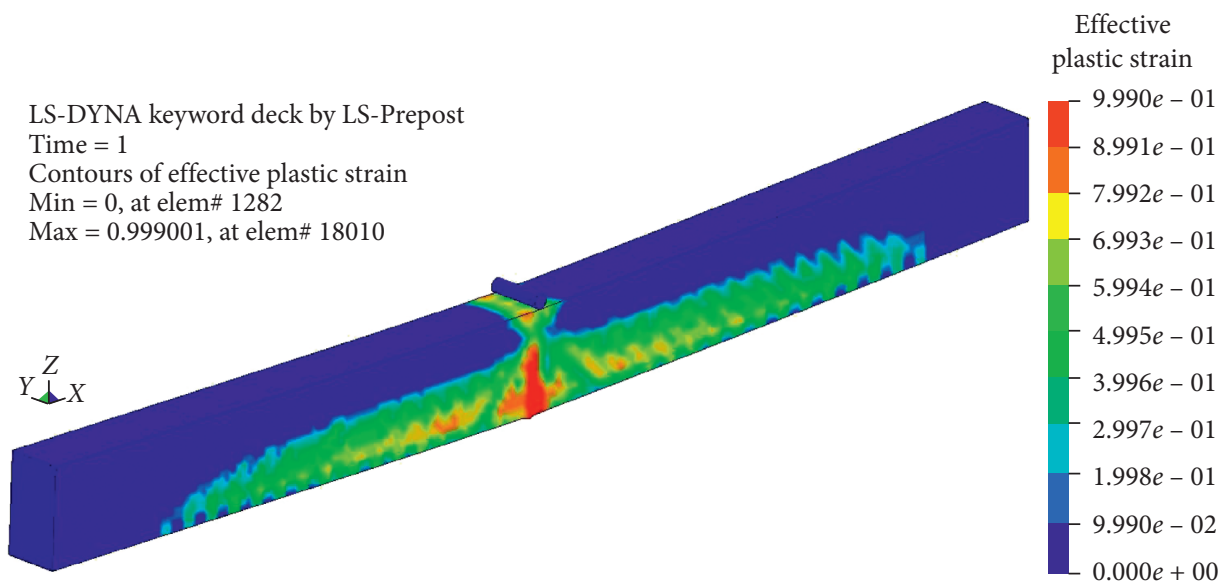

FIGURE 14: Distribution of effective plastic strain by CSCM concrete material option at the ultimate loading stage of $P=439 \mathrm{kN}$.

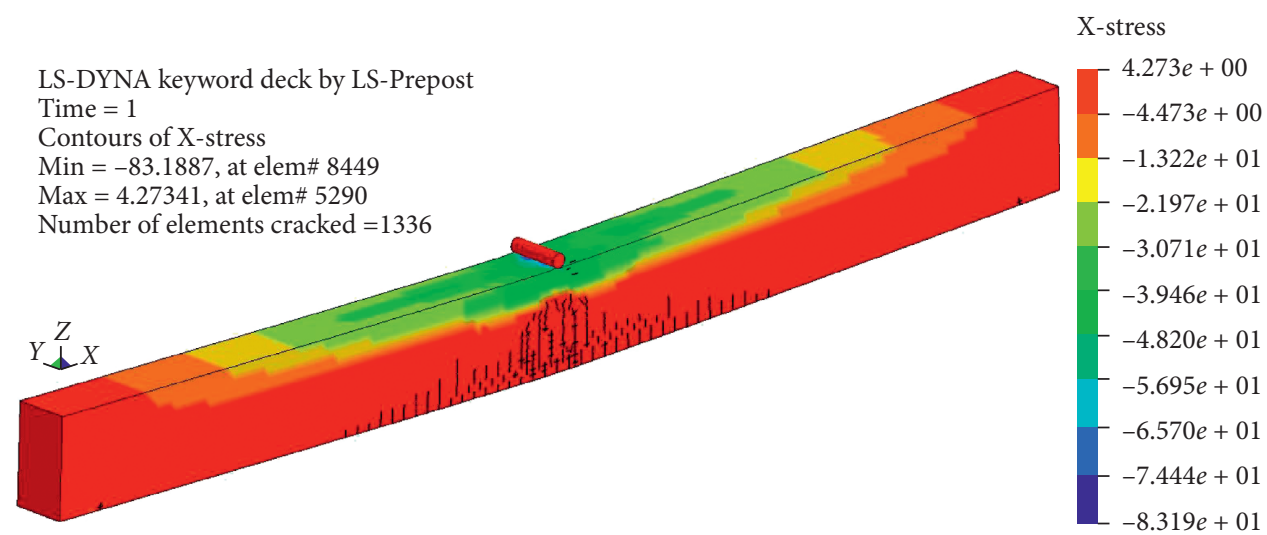

FIGURE 15: Crack pattern by Winfrith concrete material option at the ultimate loading stage of $P=424 \mathrm{kN}$.

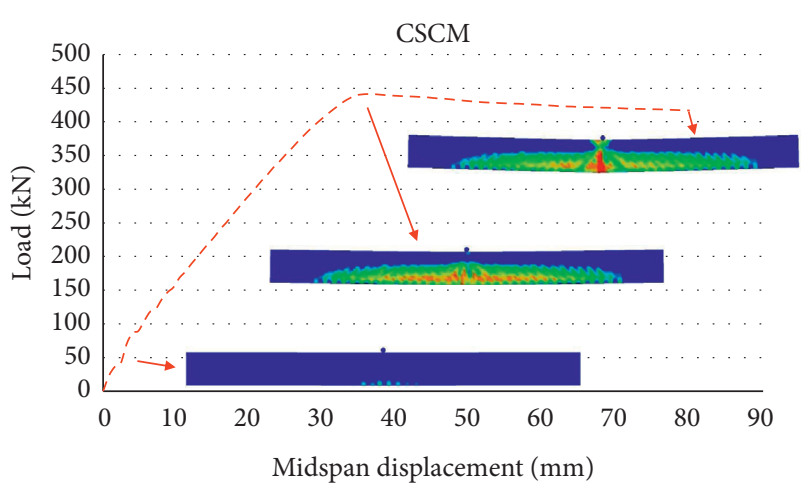

FIGURE 16: Effective plastic strains at different loading stages using CSCM concrete material option.

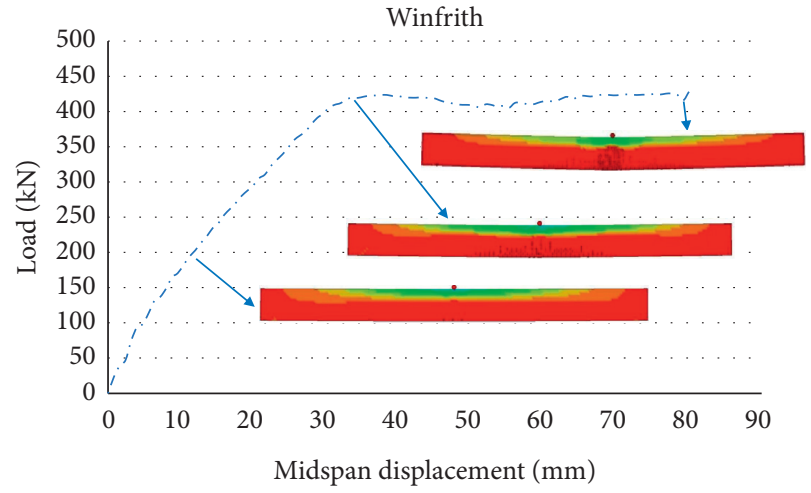

FIGURE 17: Crack development at different loading stages using Winfrith concrete material option. 
propagates upward the cross section as the applied load is reached to ultimate state.

\section{Summary and Conclusion}

Numerical analyses by discrete and CBIS finite element models have been carried out in association with LS-DYNA material options which can be used to simulate the nonlinear behavior of reinforced concrete members as well as reinforcements. The results obtained through this study are summarized in three ways. First, the discrete model analysis results and CBIS analysis results show similar load-displacement curves. Both models show sufficiently reliable results as compared with the experimental values. Second, through the convergence test, it can be seen that the CBIS model converges at much less degrees of freedom than the discrete model to obtain the same level of accuracy. Third, due to the characteristics of the model, the CBIS model can maintain a much better aspect ratio of elements. For rebar reinforced concrete structure analysis, the CBIS model can show modeling simplicity as compared with the discrete model and can reduce computer CPU time as well [24].

\section{Data Availability}

The data used to support the findings of this study are available from the corresponding author upon request.

\section{Conflicts of Interest}

The authors declare that they have no conflicts of interest.

\section{Acknowledgments}

This research was supported by the Basic Science Research Program through the National Research Foundation of Korea (NRF) funded by the Ministry of Education (NRF2020R1I1A3061349).

\section{References}

[1] G. Markou and M. Papadrakakis, "Computationally efficient 3D finite element modeling of RC structures," Computers and Concrete, vol. 12, no. 4, pp. 443-498, 2013.

[2] A. Jawdhari and I. Harik, "Finite element analysis of RC beams strengthened in flexure with CFRP rod panels," Construction and Building Materials, vol. 163, pp. 751-766, 2018.

[3] X. Guo, Y. Wang, P. Huang, and Z. Chen, "Finite element modeling for fatigue life prediction of $\mathrm{RC}$ beam strengthened with prestressed CFRP based on failure modes," Composite Structures, vol. 226, Article ID 111289, 2019.

[4] P. E. Mergos and A. J. Kappos, "A distributed shear and flexural flexibility model with shear-flexure interaction for R/C members subjected to seismic loading," Earthquake Engineering \& Structural Dynamics, vol. 37, no. 12, pp. 1349-1370, 2008.

[5] A. Saritas and F. C. Filippou, "Numerical integration of a class of $3 \mathrm{~d}$ plastic-damage concrete models and condensation of $3 \mathrm{~d}$ stress-strain relations for use in beam finite elements," Engineering Structures, vol. 31, no. 10, pp. 2327-2336, 2009.

[6] H.-G. Kwak and D.-Y. Kim, "Cracking behavior of RC panels subject to biaxial tensile stresses," Computers \& Structures, vol. 84, no. 5-6, pp. 305-317, 2006.
[7] J. S. Ahn, K. S. Woo, P. K. Basu, and J. H. Park, "P-version nonlinear analysis of RC beams and slabs strengthened with externally bonded plates," Finite Elements in Analysis and Design, vol. 42, no. 8-9, pp. 726-739, 2006.

[8] V. K. Papanikolaou and A. J. Kappos, "Numerical study of confinement effectiveness in solid and hollow reinforced concrete bridge piers: Part 2: analysis results and discussion," Engineering Structures, vol. 87, no. 21-22, pp. 1427-1439, 2009.

[9] C. Mourlas, G. Markou, and M. Papadrakakis, "Accurate and computationally efficient nonlinear static and dynamic analysis of reinforced concrete structures considering damage factors," Engineering Structures, vol. 178, pp. 258-285, 2019.

[10] M. D. Kotsovos, Finite-element Modelling of Structural Concrete: Short-Term Static and Dynamic Loading Conditions, CRC Press, Boca Raton, FL, USA, 2015.

[11] C. Mourlas, M. Papadrakakis, and G. Markou, "A computationally efficient model for the cyclic behavior of reinforced concrete structural members," Engineering Structures, vol. 141, pp. 97-125, 2017.

[12] D. M. Cotsovos, C. A. Zeris, and A. A. Abas, "Finite element modeling of structural concrete," in Proceedings of the ECCOMAS Thematic Conference on Computational Methods in Structural Dynamics and Earthquake Engineering, COMPDYN 2009, Rhodes, Greece, 2009.

[13] J. O. Hallquist, LS-DYNA Theory Manual, Livermore Software Technology Corporation (LSTC), Livermore, CA, USA, 2006.

[14] G. R. Liu and S. S. Quek, The Finite Element Method, Butterworth-Heinemann, Elsevier Science Ltd., Oxford, UK, 2003.

[15] H. G. Kwak and F. C. Filippou, "Finite element analysis of reinforced concrete structures under monotonic loads," Report No. UCB/SEMM-90/14, University of California, Berkeley, CA, USA, 1990.

[16] J. O. Hallquist, LS-DYNA Keyword User's Manual, Version 971, Livermore Software Technology Corporation (LSTC), Livermore, CS, USA, 2007.

[17] F. J. Vecchio and W. Shim, "Experimental and analytical reexamination of classic concrete beam tests," Journal of Structural Engineering, vol. 130, no. 3, pp. 460-469, 2004.

[18] R. I. Gilbert and S. Nejadi, An Experimental Study of Flexural Cracking in Reinforced Concrete Members under Short Term Loads, School of Civil and Environmental Engineering, The University of New South Wales, Kensington, Australia, 2011.

[19] B. Bresler and A. C. Scordelis, "Shear strength reinforced concrete beams," Journal of the American Concrete Institute, vol. 60 , no. 10, pp. 51-72, 1963.

[20] L. Schwer and Y. Murray, "Continuous surface cap model for geomaterial modeling, A new LS-DYNA material type," in Proceedings of the 7th International LS-DYNA Users Conference, pp. 16-35, Detroit, MI, USA, May 2002.

[21] T. A. Mohammed and A. Parvin, Vehicle Bridge Pier Collision Validation Analysis and Parametric Study Using Multiple Impact Data, FHWA Bridge Engineering Conferrence, Orlando, FL, USA, 2010.

[22] J. Adam and F. Johan, "Structural behavior of prestressed concrete beams during impact loading," Master Thesis, Chalmers University of Technology, Gothenburg, Sweden, 2015.

[23] A. T. Federico, C. B. Lawrence, and E. P. Michael, "Analysis of fiber-reinforced polymer composite grid reinforced concrete beams," ACI Structural Journal, vol. 100, no. 2, pp. 250-258, 2003.

[24] H. Chen, "An Introduction to CONSTRAINED_BEAM_IN_ SOLID," FEA Information Engineering Solutions, vol. 5, no. 10, pp. 79-83, 2016. 